\title{
Research on Overseas Investment Decision of Power Grid Project Based on Value Orientation and Risk Prevention
}

\author{
Haican Diao ${ }^{1}$, Min Wang ${ }^{1+}$ and Xinyu Lin ${ }^{1}$ \\ ${ }^{1}$ School of Business , Renmin University of China, Beijing, 100872
}

\begin{abstract}
As grid projects invest overseas, they face complex internal and external environments. Based on the comprehensive analysis of the characteristics of overseas power grid projects, this study quantifies the overseas investment value and investment risk indicators. Based on the quantitative results, three value scenarios and four risk scenarios are determined based on different investment environments. Weigh the constraint relationship between overseas investment value and investment risk of power grid project, and based on the goal of value maximization, establish a collaborative optimization model of value and risk, use genetic algorithm to solve the model to determine the optimal investment scenario combination, and In a specific scenario, the national grid is selected to analyze the project investment in Brazil, and the decision model is further optimized to provide decision-making basis for the investment of the overseas grid projects of the State Grid.
\end{abstract}

Keywords: value, risk, overseas power grid project investment, decision-making model, synergistic optimization.

\section{Introduction}

In the context of economic globalization, the global energy Internet has moved from strategic conception to practical action, in which the power grid plays an increasingly important role. Relying on the technical advantages of UHV(ultra-high voltage) and smart grid, the company develops international business actively and steadily, and vigorously develops overseas markets around the "one belt and one road" construction and construction of key areas of global energy Internet. How to establish an objective and scientific evaluation method of overseas investment value of power grid projects, rationally evaluate the investment value of overseas projects, scientifically identify and evaluate the risk of overseas investment, and study the decisionmaking of overseas investment become an important means to ensure the effectiveness of investment and improve the accuracy of investment. It is also the key to realize the optimal allocation of investment in the global scope.

However, due to the uncertainty of overseas environment and other factors, the overseas investment of China's power grid companies is not smooth sailing. Whether the project is successful or not is affected by economic, political, environmental and other factors. Therefore, power grid companies must effectively identify the risk of overseas investment, and do a good job in response measures and emergency plans, especially for a wide range of aspects. In order to improve the level of risk management, the risk management theory should be used for comprehensive analysis of projects with complex processes. The research on project investment risk management emerges in endlessly. These research results provide a reference for us to study and analyze the investment risk of power grid overseas projects, both ideologically and methodologically. For example, Zou Shuliang et al. (2013) [1] established an evaluation index system for investment risk of nuclear power projects by analyzing the characteristics of nuclear power projects; $\mathrm{Li}$ Youtian et al. (2013) [2] took overseas investment of Chinese energy enterprises as the research object,

\footnotetext{
+ Corresponding author. Min Wang. Tel.: + 18630122029; fax: +01082500482.
}

E-mail address: 18630122029@163.com. 
analyzed its current situation and characteristics, and put forward strategic suggestions for the development of energy enterprises from the two levels of government and enterprises by identifying the non-economic risks of overseas investment; Shengli et al. (2018) [3] took the process of overseas investment projects as the object, this paper uses DEA evaluation method to carry out post-evaluation analysis on the basis of constructing the post-evaluation index system of the overseas investment project process of power grid, and puts forward relevant improvement programs.

Of course, there are many similar risk research and analysis [4]-[7]. In addition, there are some literatures from the perspective of risk assessment methods, but these studies mostly focus on risk identification, risk assessment, and do not combine risk and value. The value of project investment as a direct criterion to measure the investment decision-making of enterprises is very important. With the upgrading of China's industrial structure and the acceleration of the pace of "going out", China's foreign investment has its relevant theoretical basis. Especially for power grid enterprises, which occupy an important position in the national economy, we should pay more attention to the value created by power grid investment.

Firstly, based on the summary and analysis of previous studies, this study established the overseas investment value and risk evaluation system of power grid projects, and uses the corresponding quantitative methods to measure scientifically. Then, according to the measurement results, the overseas investment value and risk of power grid projects are divided into three value scenarios and four risk scenarios respectively. Considering the objectives of value maximization and the constraint condition of risk minimization, this paper established a synergistic optimization model of risk and value. By comparing the methods of solving such optimization model, we select genetic algorithm as the solution method to get the decision-making portfolio, and further discuss the investment scale under scenario portfolio through case analysis, which provides theoretical support for the investment decision-making of power grid.

\section{The quantification of grid overseas project investment value and risk}

Based on the existing literature and comprehensive analysis of the characteristics of overseas investment in power grid, we summarized the evaluation index system of overseas investment value and risk of power grid. At the same time, according to the meaning of each index, we combine the corresponding quantitative formulas and methods (value quantification method: input-output method, benefit-cost method, etc.; risk quantification method: loss expectation value method, etc.), quantitative results are obtained from relevant data such as State Grid, National Bureau of Statistics, International Energy Agency and Wind database, which can be used as the basis for scene classification.

Due to the different situations involved in overseas investment in different countries, the investment in different countries needs to be analyzed from two dimensions: economic value and non-economic value, which are based on the investment value. The power grid investment value is divided into three value scenarios: strategic development, brand technology and investment return. And with the wide range of risks involved, the degrees of risk preference of risk subject, investment subject are different, so we consider risks from the following four angles: the greatest influence, the most easy to perform, the partner and the project characteristics. On the basis, we calculated the value and risk coefficient of different scenarios as shown in table 1 and table 2, through combining the quantitative values, and the weight of each index in the evaluation system, which provide a foundation for the subsequent model building.

Table 1: The value coefficients of different value scenarios.

\begin{tabular}{cccc}
\hline Scene & Strategic development & Brand technology & Return on Investment \\
\hline \multirow{2}{*}{ The value coefficient } & 0.052228935 & 0.042944444 & 0.059933333 \\
& & & \\
\hline
\end{tabular}


Table 2: The risk coefficients of different value scenarios.

Scene The greatest influence The most easy to perform The partner The project characteristics

\begin{tabular}{lllll}
\hline The risk coefficient & 0.5911272 & 0.45009624 & 0.18804374 & 0.35000178 \\
\hline
\end{tabular}

\section{The optimization of power grid overseas project investment}

On the basis of comprehensive analysis of power grid value and risk evaluation system, we divide it into different scenarios and use this as a basis for portfolio selection.

\subsection{The optimization model}

\subsubsection{The problem description}

Based on the scenarios of value index system and risk assessment index system, considering different scenarios of value quantification and risk quantification, this paper discusses whether different projects should invest under different scenarios, that is, to maximize the value creation of overseas investment as the optimization goal, and to minimize the risk.

Firstly, take the following two variables as decision variables:

$x_{i}(i=1,2,3)$ :The enterprise project decision-making based on the three scenarios of value-oriented of overseas project investment decision-making (strategic development, brand technology, and investment return), that is, whether the enterprise invests in the project under this scenario, so $x_{i}$ is a variable of $0-1$;

$y_{j}(j=1,2,3,4)$ :The enterprise project decision-making under the four risk scenarios (the greatest impact, the easiest execution, the partner and the project characteristics), that is, whether the enterprise invests in the project under this scenario, so $y_{i}$ is also a $0-1$ variable.

Secondly, the relevant parameters and other variables involved in the process of model building are shown below:

$v_{\mathrm{i}}(i=1,2,3)$ :The value creation coefficient of different scenarios under the value orientation, which is measured by the weighted summation of the quantized values of the corresponding relevant value indexes under the scenario;

$r_{\mathrm{j}}(j=1,2,3,4)$ :The risk coefficient of different scenarios under the risk assessment, which is measured by the weighted summation of the corresponding quantized values of relevant risk indicators in the scenario;

$V$ :The threshold of value creation (the minimum value of value creation that an enterprise must satisfy), which is can be determined by combining literature and quantitative index system;

$R$ :The risk expectation threshold (the maximum risk that an enterprise can bear), which can be determined by combining literature and quantitative index system.

$E_{z}(z=1,2, \ldots, \mathrm{n})$ :The creation value of the $\mathrm{n}$-th project. Since the value creation of the project investment is most directly reflected by the investment income, it can be calculated based on the investment revenue, that is, investment operation income $C I$ - investment operation cost $C O$;

$E:$ The total value of all projects created.

\subsubsection{The collaborative optimization model}

Based on the above description of collaborative optimization problem, the following collaborative optimization model is constructed, including objective function and constraints.

Max $\quad E=\sum_{z=1}^{n} \sum_{j=1}^{4} \sum_{i=1}^{3} x_{i} y_{j} E_{z} \quad(n$ means there are $n$ alternative investment projects $)$

S.t.

$$
\sum_{i=1}^{3} v_{i} x_{i} \geq V
$$

$$
\sum_{j=1}^{4} r_{j} y_{j} \leq R
$$




$$
\begin{aligned}
& E_{z}=C I_{z}-C O_{z} \\
& x_{\mathrm{i}}=\{0 ; 1\} ; \quad y_{\mathrm{j}}=\{0 ; 1\} ; \quad i=1,2,3 ; j=1,2,3,4 ; \quad z=1,2, \ldots, \mathrm{n}
\end{aligned}
$$

Max $E$ represents maximum value creation, i.e. $n$ projects make investment decisions under different scenarios; formula (1) represents the minimum value constraint; formula (2) represents the maximum constraint of the risk; formula (3) represents the investment return of project $\mathrm{z}$; and formula (4) represents the decision variables are $0-1$ variables.

\subsection{The investment decision-making model}

\subsubsection{The problem description}

Furthermore, based on the overseas project investment synergistic optimization of risk and value, project decision-makers can determine how to set different investment quotas to maximize NPV value of project portfolio under the restriction of total investment quota. The selection of NPV as the main criterion to measure the value of project investment. Therefore, the decision variables of the decision-making problem are the investment quota of each project, and the objective function is to maximize the NPV value of the total investment of the project. The corresponding parameters and variables are expressed as follows:

$C_{\mathrm{it}}$ : Decision variable, representing the investment amount of different projects in the $t$ period, where $i$ represents different projects, $i=1,2, \ldots$;

$R_{\mathrm{iT}}:$ : Represents the expected return of different projects in the $T$ period, usually $T>t$. Assuming that the project investment occurs in the $t$ period, and generates the return in the $T$ period, and the return is a linear function based on the investment cost;

$\alpha$ : The discount rate; $\gamma_{\mathrm{i}}$ : The expect return rate of project $i$;

$C$ : The total amount of project investment, that is, the total amount of all project investment should be less than $C$.

Authors submitting a manuscript do so on the understanding that if the manuscript is accepted for publication, copyright for the article, including the right to reproduce the article in all forms and media, shall be assigned exclusively to the Publisher.

\subsubsection{The investment decision model}

$$
\begin{array}{ll}
\text { Max } \quad \mathrm{NPV}=\sum_{i=1}^{n} R_{i T_{i}} e^{-\alpha T_{i}}- & \sum_{i=1}^{n} C_{i t} e^{-\alpha T_{i}} \\
\text { S.t. } & \sum_{i=1}^{n} C_{i t} \leq C \\
& R_{i T_{i}}=C_{i t}\left(1+\gamma_{i}\right) \\
& C_{i t} \geq 0
\end{array}
$$

Max NPV is the objective function and represents the maximization of net present value; formula (5) represents the constraint condition of the total investment amount of the project; formula (6) indicates that the expected return of each project is a linear function based on its expected return rate; formula (7) indicating that project investment cannot be negative.

Note: Generally, in the process of project investment, the current project does not generate income, but generates income in the next period or several periods after the investment, so here we assume that $T=t+T_{i}$, and $t=1$, that is, all projects are invested in the first period, and here we take one year as a period. (The $T_{i}$ is the interval period from the project investment to income generation.)

\section{An example of overseas investment model for power grid}

\subsection{Case selection}

Firstly, based on the relevant data of the State Grid's overseas investment in 2016, the Brazilian investment project is selected as a typical case analysis. How to choose the investment scenario under the 
collaborative optimization model; then, in a certain scenario, further decide the amount of funds allocated. Table 3 lists a list of state grid companies' investment projects in Brazil.

Table 3: The list of investment projects in Brazil.

\begin{tabular}{lllll}
\hline Num & The project name & $\begin{array}{l}\text { The investment } \\
\text { volume(BOU) }\end{array}$ & $\begin{array}{l}\text { Equity ratio } \\
\text { for SGCC }\end{array}$ & $\begin{array}{l}\text { Investment } \\
\text { properties }\end{array}$ \\
\hline 1 & $\begin{array}{l}\text { Full acquisition of seven Brazilian } \\
\text { transmission concessions }\end{array}$ & $9 . .89$ & $100 \%$ & M\&A \\
2 & $\begin{array}{l}\text { Acquisition of Brazilian ACS company's } \\
\text { transmission assets }\end{array}$ & 11.13 & $100 \%$ & $\begin{array}{c}\text { M\&A, greenfield } \\
\text { projects } \\
\text { greenfield projects }\end{array}$ \\
4 & $\begin{array}{l}\text { Extension Project of 500 kV Louisiana } \\
\text { Substation and 230 kV Nigger Substation } \\
\text { Terry Pierce Power Transmission Franchise }\end{array}$ & 0.22 & $51 \%$ & greenfield projects \\
5 & $\begin{array}{l}\text { Project } \\
\text { Brazil Beautiful Landscape +800 KV }\end{array}$ & 11.41 & $51 \%$ & greenfield projects \\
6 & $\begin{array}{l}\text { UHVDC Delivery Franchise Project (Phase 1) } \\
\text { Brazil Beautiful Landscape +800 KV } \\
\text { UHVDC Delivery Franchise Project (Phase 2) }\end{array}$ & 25 & $100 \%$ & greenfield projects \\
\hline
\end{tabular}

Brazil's beautiful landscape $\pm 800 \mathrm{kV}$ high-voltage DC sent out the concession rights project Phase II is the first UHV transmission project of the State Grid Corporation to independently carry out engineering general contracting (EPC) overseas. In view of the significance of investment projects in Brazil by the State Grid, we consider how to allocate funds (amount of investment) to maximize the value of investment in similar countries. We can choose countries with similar Brazilian scenarios as the host countries of preinvestment to make decision analysis, that is, to decide to invest in those above five type projects(item 5 and 6 are treated as a single project, that is 5), through the model to calculate how to allocate the investment of each project.

\subsection{Algorithm selection}

According to the constructed model, we choose the genetic algorithm to solve. Before solving the model, firstly, we need to calculate the relevant parameters in the model, including value creation coefficient $v_{i}(i=$ $1,2,3)$ in different scenarios under value orientation, risk coefficient $r_{j}(j=1,2,3,4)$ in different scenarios under risk assessment, value creation threshold $V_{i}(i=1,2,3)$ in different scenarios and risk expectation threshold $R_{j}(j=1,2,3,4)$ in different scenarios.

(1)Different value scenarios coefficient $v_{i}$ and different risk scenarios coefficient $r_{i}$

According to the value scenario and risk scenario coefficients obtained from the above quantization results, $v_{i}$ and $r_{j}$ values are respectively shown in table 4 below:

Table 4: the value and risk coefficient.

\begin{tabular}{cccccccc}
\hline Num & $\boldsymbol{v}_{\boldsymbol{1}}$ & $\boldsymbol{v}_{\boldsymbol{2}}$ & $\boldsymbol{v}_{\boldsymbol{3}}$ & $\boldsymbol{r}_{\boldsymbol{1}}$ & $\boldsymbol{r}_{\boldsymbol{2}}$ & $\boldsymbol{r}_{\mathbf{3}}$ & $\boldsymbol{r}_{\boldsymbol{4}}$ \\
\hline Coefficient & 0.052228935 & 0.042944444 & 0.059933333 & 0.5911272 & 0.45009624 & 0.18804374 & 0.35000178
\end{tabular}

(2)The value creation threshold $V$

Value creation threshold refers to the minimum value creation of a project when making investment decisions. In order to ensure the dimensionality of all indicators in the process of monetary quantification, the growth rate of indicators is calculated, so as to avoid the error caused by the unit level of indicators. At the same time, the growth rate can reflect the growth of value creation very well, so we choose a small growth rate of $5 \%$ as the minimum threshold of value creation, that is $V=0.05$.

(3)The risk expectation threshold $R$

The risk expectation threshold here is determined as a reasonable threshold according to the actual situation of the grid project investment, So the threshold $R=$ the maximum probability of risk occurrence * the expected loss of risk occurrence. The expected loss value of risk is determined synthetically by experts' scoring. The scoring range is 1-5. Therefore, the maximum expected loss is set to be 5 . Because of the randomness of the risk occurrence, the probability varies with the characteristics, structure and environment of the project. Therefore, in order to minimize the risk occurrence, the maximum probability of risk occurrence is set to be $20 \%$, so the risk expectation threshold $\mathrm{R}=5 * 20 \%=1$. 
In addition, for $E_{z}$ in the decision-making model, it represents the investment income of project $z$. Because the income of power grid overseas investment projects is different from each other, the total income of $n$ projects is taken here. Based on the obtained data of power grid investment, the $E z$ value is taken here as the total income of all projects of power grid overseas investment in 2016, that is, 67.5 billion yuan.

The parameters of the decision-making model have been set up. On this basis, the model is solved by using MATLAB.

The results show that the optimal value of all decision variables is 1 , that is, under the constraint of meeting the minimum value creation and the highest risk expectation, all scenarios can be invested. At this time, the project meets the value maximization, that is, under the arrangement and combination of 12 scenarios based on risk prevention and value orientation, enterprises adopt investment projects. At this time, the maximum value creation is as follows:

$$
\operatorname{Max} \mathrm{E}=12 \times 675=8100(100 \text { million })
$$

\subsection{The result analysis}

Based on the total investment in Brazil's project investment process, we regard it as the limit of investment in countries with similar scenarios, namely

$$
\mathrm{C}=9.89+11.13+0.22+11.4+18+25=75.64 \text { (BOU) }
$$

that is $\sum_{i=1}^{5} C_{i 1} \leq 75.64$, at the same time, according to the existing data, we get the expected return rate and income interval of each project, as shown in the following table 5:

Table 5: Expected return rate and interval period of various projects.

\begin{tabular}{cccccc}
\hline The project & $\mathbf{1}$ & $\mathbf{2}$ & $\mathbf{3}$ & $\mathbf{4}$ & $\mathbf{5}$ \\
\hline $\begin{array}{c}\text { Expected return rate( } \%) \\
\text { The interval period } \\
\text { (year) }\end{array}$ & $4.5 \%$ & $4.54 \%$ & $3 \%$ & $4.55 \%$ & $5 \%$ \\
& 1 & 2 & 1 & 2 & 5
\end{tabular}

In addition, in order to simplify the model, we assume that all projects are invested in the first phase, and when calculating the net cash flow of the project, we generally take the discount rate $\alpha=5 \%$. Based on the above information, we use Matlab to optimize the project investment decision-making model and get the results as shown in Table 6 below.

\begin{tabular}{lllllll}
\multicolumn{7}{c}{ Table 6: The investment decision result. } \\
\hline Variable & $\boldsymbol{X}_{\boldsymbol{1}}$ & $\boldsymbol{X}_{\mathbf{2}}$ & $\boldsymbol{X}_{3}$ & $\boldsymbol{X}_{\mathbf{4}}$ & $\boldsymbol{X}_{5}$ & NPV \\
\hline optimal value(BOU) & 74.13 & 0.32 & 0.00 & 0.94 & 0.25 & 3.2344
\end{tabular}

According to the results in table 6 , when the amount of investment in five types projects are 74.13, 0.32 , $0.00,0.94$ and 0.25 billion dollars respectively, the net present value of enterprise project investment is the largest, reaching 333.44 million dollars.

\section{Conclusion and discussion}

Based on the comprehensive analysis of the characteristics of overseas power grid projects, this study obtains different investment value scenarios and risk scenarios based on quantitative results and analysis, and builds a grid project overseas investment risk and value synergy optimization model and investment decision model. By selecting the genetic algorithm to solve the model, it is found that when the enterprise invests in overseas projects, it should meet the scenario application and invest, and the project value creation reaches the maximum. At the same time, based on a specific scenario, for different project selection, based on the decision-making model structure, through case analysis of specific investment decisions, it provides a more scientific and standardized basis for power grid project investment decisions.

However, in the actual project investment, there will be some large-scale projects with long investment period and long-term income interval. This involves whether the enterprise funds can be returned in time, whether the capital chain is broken or not, and the project dynamic investment for such problems can be used as a project. Subsequent research expands further analysis. 


\section{References}

[1] Zou Shuliang, Qiu Wenlin, Liu Wenjun. The Construction of Investment Risk Assessment Index System for Nuclear Power Projects[J]. Sino-Global Energy, 2013, 18(12): 25-29.

[2] Li Youtian, Li Runguo, Zhai Yusheng. Study on the non-economic risk of Chinese energy enterprises' overseas investment[J]. Management World, 2013(5):1-11.

[3] Zhao Shengli, Li Xiaobing, Yang Yuqun, Sun Bin, Li Bo. Grid Construction Overseas Investment Process Post-Evaluation base on DEA[J]. Power System and Clean Energy, 2018, 34(1): 39-44.

[4] Zhao Wei. Research on the political risk of China's high-speed railway "going out" under the "One Belt And One Road" strategy[J]. Foreign trade, 2016(8):53-58.

[5] Liang Jingbo. Political Risks and Countermeasures of Overseas Investment of Chinese Enterprises[J]. Truth Seeking, 2013(4): 40-44.

[6] Gao Yanfang. Risk management of overseas investment under the background of "one belt and one road"[J]. Financial Communication, 2017(2):119-121.

[7] Wang Fanyi. The prospect and risk prevention of China's foreign investment under the "one belt and one way" strategy[J]. Economic Review, 2016(7): 33-36. 